needs great circumspection, but the results sometimes fully reward the severity of its action. The drumhead should always be studied after any of these procedures, and the effect noted. Pneumatio massage with the Siegle's speculum can profitably follow in almost all cases.

Finally, as to the value of such treatment, many a case of hypertrophic or solerotic deafness, which has been growing steadily worse under Politzer inflations and good nasopharyngeal treatment, will hail with delight the immediately greater and more lasting gain from the catheter treatment. The duration of the benefit will grow longer with each repetition for four or five weeks-when it ceases to extend it is generally time to remit treatment, having the patient use, sev-

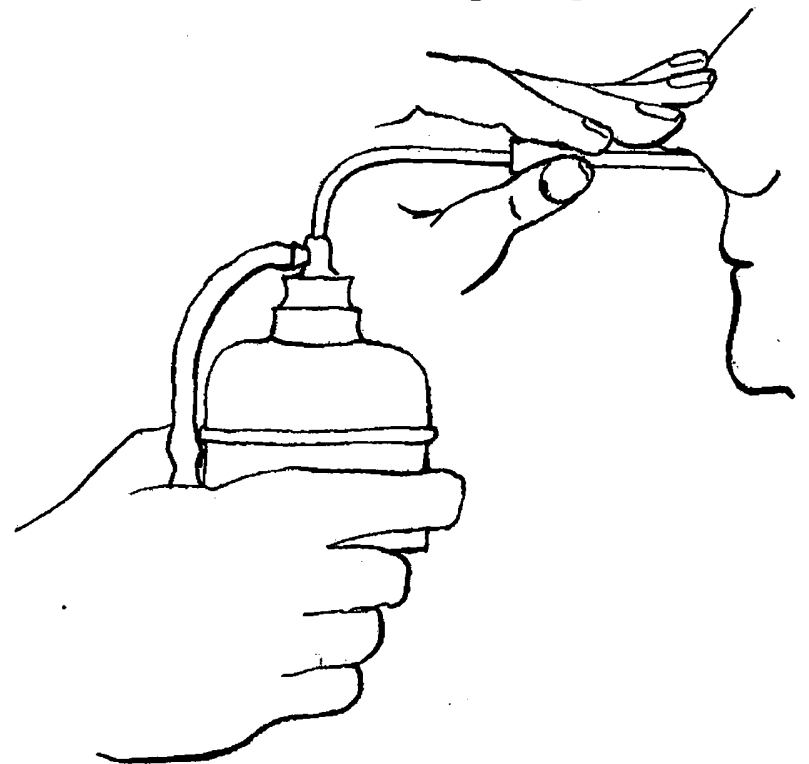

Fig. 3.-Atomizer used in catheter for inflation, tubal spraying and injection of fluid into the tympanic cavity.

eral times eash day, gargling for its gymnastic effect, and pneumatic massage with the finger tip. After a few weeks, treatment by the catheter can be resumed with further gain for four or five more weeks. As a result the patient will probably have gained most of what is possible in the case and should have a short course semi-annually thereafter to prevent backsliding and to test the possibilities of further gain.

The restoration of hearing may be very incomplete, our tests showing that it is but a small fraction of the normal and that the defect is still very great. Yet this pitiable remnant may be many times as much as the patient had before treatment and a source of great satisfaction and benefit to the sufferer and friends; while the negative gain is no small one that farther loss and its overwhelming disaster has been converted into moderate but most comfortable gain in hearing.

AT THE recent meeting of the Illinois State Medical Society, a resolution was adopted by a unanimous vote warmly thanking Governor Tanner for the interest he has manifested during the past two years in the cause of legitimate medicine and the interest of the people, by aiding the passing of salutary, and preventing the enactment of improper, medical and sanitary laws. This society was organized in 1850 at Springfield, and next May will hold its fiftieth anniversary in the same city. Dr. Harold N. Moyer of Chicago will have the honor of presiding over the jubilee meeting.

\section{AMPUTATION OF THE BREAST.}

BY MEANS OF THE ANTERIOR AXILLARY INCISION. BY EMANUEL J. SENN, M.D.

Associate in Surgery, Rush Medical College, in affiliation with the University of Chicago; Assistant-Surgeon St. Joseph's Hospital; A ssistant-Surgeon Presbyterian Hospital.

$$
\text { CHICAGO. }
$$

Amputation of the breast in malignant disease is no longer regarded as a palliative operation in prolonging life; but should have for its purpose a permanent result, as verified by recent statistics. The operative technic of Halsted, which is simply a practical application of the profound anatomic research of Haidenhain in this region is certainly to be recommended. Of late, I have removed the breast, together with the axillary contents, without making an incision in the axilla.

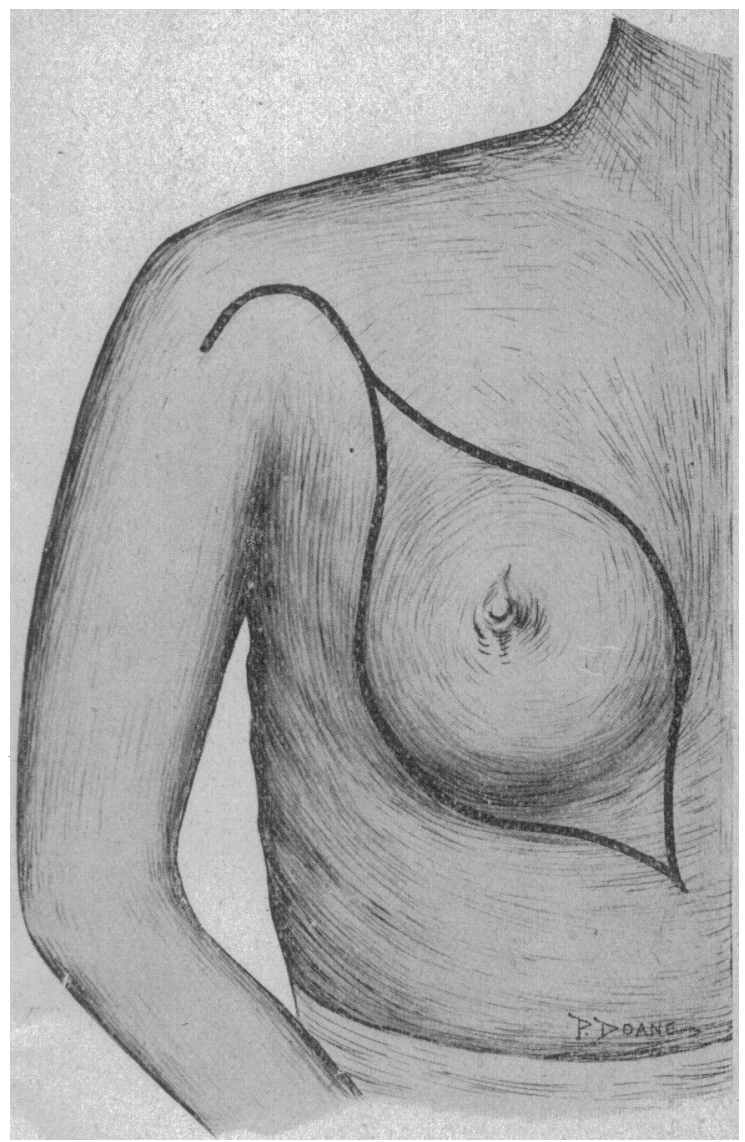

The object of this short article is not to describe the radical operation for removal of the breast, which is only too well treated in all works on operative surgery, but to dwell on the value of the anterior axillary incision as a preliminary. The accompanying illustrations are more explicit than a detailed description of the operation. The breast is circumsoribed by two ourvilinear incisions which meet above at the border of the pectoralis major muscle. The incision is then continued slightly internal to the outer border of this muscle, in an upward direction, to a point about one inch above the apex of the axilla, where it takes an outward course in the deltoid region, forming a gradual curve, which terminates at the level of the apex of the axilla. (Fig. 1.)

Figure 2 shows the breast removed from the thoracic wall, but suspended by the axillary glands and adipose tissue, which are about to be enucleated en 
masse by blunt dissection. Figure 3 represents the operation completed.

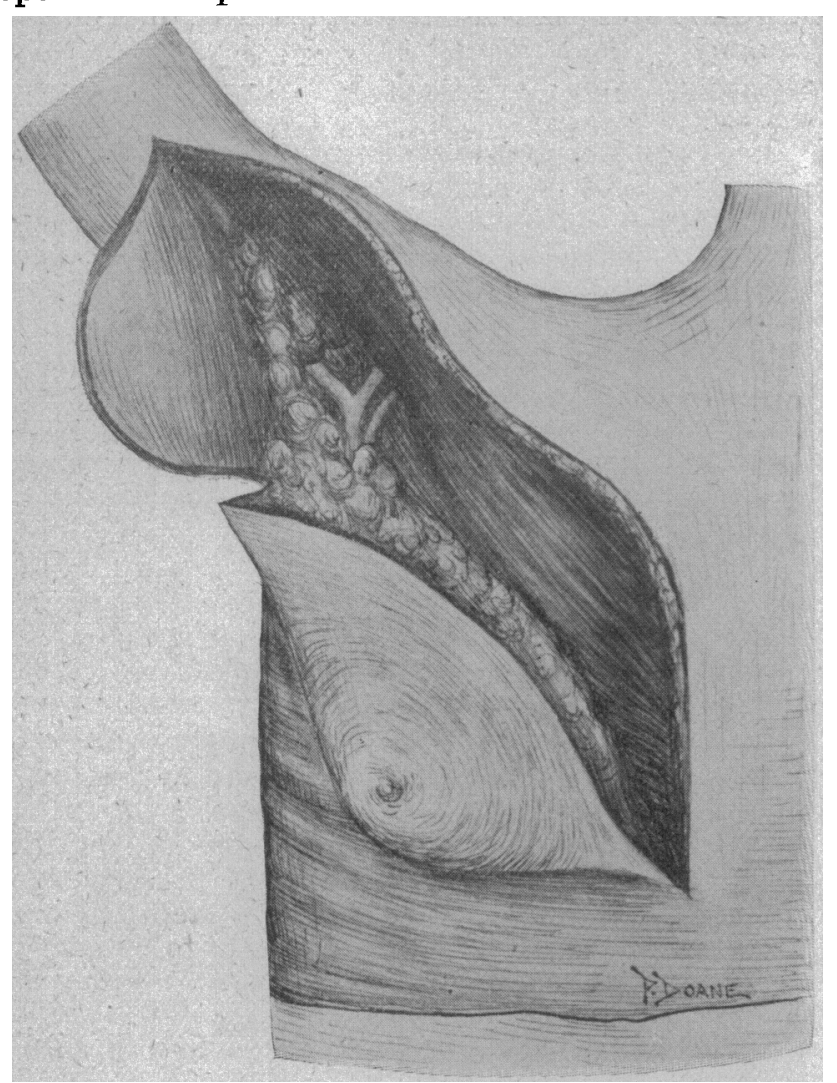

I wish to lay stress on the following advantages of the anterior axillary incision:

1. It exposes to the operator a larger field for radical work than the ordinary axillary incision.

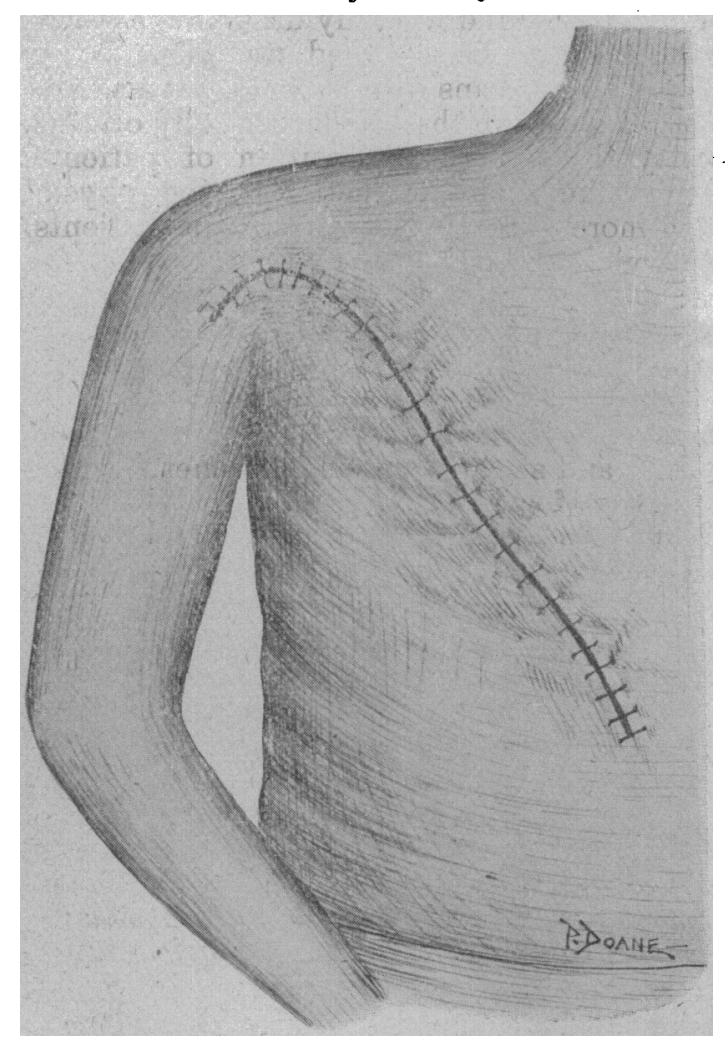

2. By making traction on the axillary flap, it is easily freed from the subcutaneous tissues with a few strokes of the knife, exposing at once the position of the axillary vein.

3 . Injury to the vein is greatly diminished, because the incision bares all the surrounding muscular landmarks to this important structure. Moreover dissection is done away from the vein instead of toward the vein, as must be done through an incision in the axilla.

4. The axillary space is unfavorable to primary wound healing, being often the seat of a fistula long after the rest of the wound has healed intact. It is a region difficult to render aseptic; hence the advantage of access to this region from without.

5. The incision is so situated that it does not im. pede free motion of the arm, the patient being able to extend the arm to the head at the first dressing. There is no subsequent cicatricial contraction, as in an axillary scar, to interfere with the physiologic function of the arm.

6 . The cicatrix is not dragged upon by motion of the arm, consequently scar tissue is little exposed to trauma through mechanic stretching; hence the diminished liability of recurrence of the disease.

\section{THE MEDICAL WITNESS.*}

HIS RIGHTS AND WRONGS IN COURTS OF JUSTICE.

\section{BY JAMES B. BAIRD, M.D.} ATLANTA, GA.

Unquestionably the medical witness has some rights, and as surely does he suffer many wrongs. The rights, briefly stated, refer to the proper treatment of the physician on the witness stand; to a just recugnition of the relationship existing, or which ought to exist, between the physician and his patient; and to a true valuation of his expert services. The wrongs, in a word, relate to a misconception of bis rights, br to an utter disregard of them.

The treatment accorded the physician on the stand depends, in great measure upon the witness himself, and in part upon the court and the attorneys engaged in a given case. But few lawyers-none of the better class - will undertake to mistreat a medical witness who demeans himself with propriety, who actually possesses the information which he claims, or ought to have, and who gives his evidence or states his opinion in a simple, straightforward manner, without seek. ing to magnify himself, to dazzle his hearers by a display of profound erudition, or by the assumption of a degree of knowledge which he does not possess. But few judges will permit a competent and sincere witness to be badgered, bullied or ridiculed, even if such tactics should be attempted by a discourteous attorney.

If the principal object of all legal proceedings in court were simply to ascertain and to establish the truth, the task set before the expert witness would be greatly simplified. There would then be no incentive to confuse, to mislead or to combat the witness. But, unfortunately, such a purpose is not usually a predominant influence. Each side is intent on sustaining its own contention, and each seeks testimony tending to strengthen the position of the advocate. Hence, questions are adroitly framed, and answers are often ingeniously warped or distorted with the design of eithef impressing or suppressing certain salient points, 